enough by Health authorities taking into account the burden of the disease. AFLAR has fostered dynamics by creating a structure called the National Alliance against OA, includes national experts, patients and health professionals (HP). A initiative of this group has been to organize the first General Convention for OA. Objectives: Its main challenge was to provide a list of actions that could potentially change the face of the disease and improve the visibility of $\mathrm{OA}$ along with the needs and demands from French patients.

Methods: 10 regional roundtables (with HP, patients and health institutions, around five topics) has been launched with discussions and debates and enabled the production of patient-related proposals in order to improve their care and information.

Results: 79 proposals have been selected and submitted to an online vote in order to be prioritized. Among the 5 topics addressed by the regional roundtables, cross-cutting issues were identified and 9 fields of action emerged. The final proposals were synthesized in a White Paper document and presented to the national Senate assembly. After it was broadcast to the health and public authorities in a prospect of lobbying. see in the image.

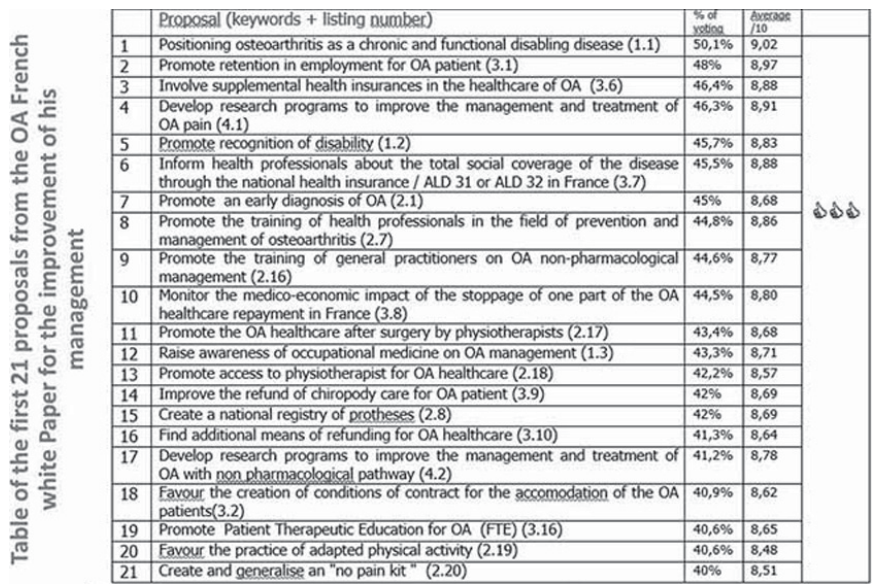

Conclusions: Although the impact of this initiative is not yet measurable, we think that it should improve the awareness of the decision-makers on the burden of the disease and provide concrete ideas to governmental and non-governmental policy makers in order to improve the quality of life of OA patients.

Acknowledgements: L. Euller-Ziegler F. Blanchet F. Beroud CE Bouvier D.Romain Bertholon, SANOIA,SNMR,CFMR. With support of Genévrier, Pierre Fabre, Expanscience Rottapharm Meda laboratory, SOFMER, CONMK \& AFLAR Disclosure of Interest: None declared

DOI: 10.1136/annrheumdis-2017-eular.1464

\section{OP0279-PARE NRAS KNOW YOUR DAS APP SELF ASSESSMENT TOOL EMPOWERING PATIENTS}

C.B. Jacklin ${ }^{1}$, S. Arora ${ }^{2} \cdot{ }^{1}$ External Affairs; ${ }^{2}$ Media \& Communications, National Rheumatoid Arthritis Society, Maidenhead, United Kingdom

Background: NRAS has worked with Roche/Chugai for many years on the Know Your DAS resources. As the DAS28 is the most utilised disease measuring tool available and is used in many countries as part of the access criteria

Objectives: In 2015 the charity was approached about developing an app for mobile phone and tablet use to encourage DAS patient self-assessment. As well as developing the app we worked with the pharmaceutical company to develop printed updated booklets for both patients and health professionals with the addition of information on DAS self-assessment contained within. With increasing pressures on rheumatology clinic time and the emphasis on improving patient education and empowerment this additional NRAS resource is timely and much in demand.

Methods: The Know Your Das app was designed with clear step by step guides and how to video clips to demonstrate how to use the app and show how patients should examine their own joints.

NRAS hosted two user testing focus group meetings and after the launch of version one real time use was analysed. In Jan 2017 version two was released with improvements to the usability and additions including sections on adherence and stock management to aid with prescription refills.

The information entered is held securely by the individual but the DAS results can be printed off or emailed to their clinicians as appropriate. It is not envisaged that the patients' self-assessment should entirely replace the clinicians' DAS measurements but that it will facilitate a better dialogue at clinic appointments as it will give a clearer picture of how the disease has been active or not in the intervening time between appointments.

Results: As of January 2017, 2217 people have downloaded the Know your DAS app and much interest has been shown by users from outside the UK who would like to be able to use the app. Clinicians are keen to utilise the app with their patients
Conclusions: Further research needs to be carried out to compare patients adherence, engagement with their clinicians and ownership of their disease managment as a direct result of using the Know Your DAS app.

Acknowledgements: Roche/Chugai Pharmaceuticals for their funding and development of this resource

Disclosure of Interest: C. Jacklin Grant/research support from: Roche/Chugai Pharmaceuticals, S. Arora: None declared DOI: 10.1136/annrheumdis-2017-eular.1931

\section{OP0280-PARE PATIENT PANELS ON ACCESS AND ADHERENCE TO TREATMENT FOR SLE PATIENTS}

S. Badreh, J. Andersen, A. Charlet, K. Lerstrøm, K.H. Wheeler. Lupus Europe, Essex, United Kingdom

Background: At the LUPUS EUROPE [forward abbreviated with LE] 2013 Convention in Paris, Professor N. Costedoat-Chalumet illustrated to the participants the critical issue of adherence to treatment (or more precisely, the lack of it). For many reasons, adhering to the prescribed treatment is a challenge for people living with Lupus, yet, "medicine only works if you take it". Understanding this area is critically important to helping people with lupus improve their quality of life.

Objectives: In LE, we wanted to know the reason(s) for this lack of adherence and how to improve it. Is lack of access also a reason for not adhering to treatment? Methods: Two patient panels were formed to conduct in depth discussion about treatment. For each panel we invited people from our European community through our member groups. The panels were organised to represent different aspects like gender, age, time of diagnosis, main disease area and representing different countries. It was important to LE, that both patient panels were conducted by and for people living with lupus, which gives the participants a feeling of security and being understood: this is very important if you want them to share their experiences openly.

LE organised the first patient panel on November 2nd-4th 2015, bringing together 10 people living with lupus, from 7 countries, to share their experience about "treatment", with a view to help improving the quality of life of people living with lupus. The second patient panel took place on March 11-13, 2016 bringing together 9 lupus affected people from all over Europe to further explore the burden of living with lupus, and to dive into the burden of daily treatment.

The panels were conducted through a series of interactive presentations, team discussions and working groups.

Results: The key findings of both patient panels were:

1. Because "Treatment" is broad; it is both medicine based and non-drug based, and can be categorised in three ways - core, medical, and well-being; there needs to be a more holistic approach to the patient.

2. Access includes ease of contact with Health Care Practitioners, support services such as orthotics and quality information as well as availability of medicines.

3. Patients will take new medicine, provided they understand the reasons why and the side effects.

4. Each patient is responsible for their own treatment and must realise that a positive mind-set can be decisive for the treatment of the disease.

5. Patient Organisations have a critical role to play, creating a community, sharing reliable information, providing hope, raising awareness and advocating for lupus. Conclusions: Organising a patient panel with a small closed group of patients on neutral ground in a "safe" environment has proven to be a good way of getting the patients to speak openly about a difficult subject and to reveal things, that they might not tell the health professionals. Through this initiative LE has gathered important information about access and adherence to treatment that we can now use to make suggestions about treatment and implement into our strategic plan for the years to come.

Disclosure of Interest: None declared

DOI: 10.1136/annrheumdis-2017-eular.2541

\section{OP0281-PARE EDUCATING PATIENT EXPERTS/PATIENT PARTNERS - A NEW WAY}

A. Phoka Charalambous ${ }^{1}$, I. Cederlund ${ }^{2}$, M. Neylander ${ }^{2} .{ }^{1}$ Cyprus League Against Rheumatism, Nicosia, Cyprus; ${ }^{2}$ The Swedish Rheumatism Organisation, Stockholm, Sweden

Background: Patients general well-being is largely dependent on health care professionals. The education of these is therefore very important. It is more and more common using patients in the education of health care professionals. The Universities in Cyprus together with other health professional groups have shown interest in involving patients with RheumatoMusculoSceletalDiseases (RMDs) in the education of medical school students regarding RMDs. Besides discussing the disease, they will also learn about the obstacles faced by the patients as well as the impact on their daily life. Through this initiative, the hope is that early recognition and diagnosis is promoted as well as enhancing the knowledge and skills of future doctors.

Objectives: The aim of this project was to implement a Patient Expert project in Cyprus League Against Rheumatism (CYPLAR), and through it train RMD patients to educate medical students and other healthcare professionals regarding 
RMDs. A learning partnership should be created between undergraduate medical students/healthcare professionals and the patient experts.

Methods: CYPLAR approached the Swedish Rheumatism Association for collaboration in order to implement the Patient Expert Project in CYPLAR.Funding was received from the EULAR Knowledge Transfer Programme. The collaboration was planned to consist of two meetings, one in Sweden and one in Cyprus.

1. Sweden: Two patients, members of CYPLAR, with RMDs, together with a Rheumatologist from CYPRUS visited the Swedish Rheumatism Association in Stockholm to learn about the Patient Partner Project, and receive Patient Expert training.

2. Cyprus: Two Patient Partner Instructors from the Swedish Rheumatism Association went to Cyprus 6 months after to oversee the progress of the Patient Expert programme and to make an examination of the two Patient Partners educated in Stockholm.

Results: The training session in Stockholm took place on May 2016, for two patients. They received training following the Swedish Patient Expert programme. This training was conducted by two Patient Expert Instructors, one rheumatologist and one Patient Expert. A visit to the Karolinska University Hospital with a tour of the Rheumatology Clinic and a Patient Expert demonstration was also included. The visit ended with a detailed plan formed for the implementation of the Patient Expert programme in CYPLAR.

The visit of the Swedish delegation took place in October 2016. Eight patients participated in the training. The training was made through workshops by the delegates from both organizations together with a Professor of rheumatology and a communication lecturer at the St George's University of London in Nicosia's establishments. Medical students were also involved in discussing their experience in being educated by patients. The programme also involved practice of joint examinations. The workshop was evaluated by the participants on the final day. After the workshop was concluded delegates spent a day discussing the event together. The programme was evaluated, and a future plan of action decided upon.

Conclusions: The implementation of the patient expert programme was successful.10 new Patient Experts are now available in CYPLAR. The next generation of health professionals will benefit and get a larger understanding of RMD's and in the end, the patients will benefit because the health care staff has a greater knowledge.

Disclosure of Interest: None declared

DOI: 10.1136/annrheumdis-2017-eular.3705

\section{OP0282-PARE \#DOESNTSHOWDOESNTEXIST / \#SYNSINTEFINNSINTE - A PHOTO CAMPAIGN BY UNGA REUMATIKER}

\section{K. Nordlund, M. Beermann. Unga Reumatiker, Stockholm, Sweden}

Background: "Rheumatism amongst young people, is that really a thing?" "Isn't rheumatism something that only old people have?" "You seem so happy and so active, surely you can't be in pain?" These are all questions that young people with rheumatism have to listen to, and answer every day.

Yes, it's possible to have rheumatism even as a young person, and to be in pain, even though we're not letting it show. We know adjustment is possible, and that we can live our life to the fullest and follow our dreams, despite rheumatism. But sometimes it demands some extra understanding from the people around us. That's what we wanted to recognize, and created a campaign together with AbbVie.

Objectives: It can be hard to understand and fully grasp something you can't see, something that is invisible. But as young people with rheumatism, we have to live and deal with our swollen joints, with the pain and the fatigue, and with the side effects of our medication. None of which should be questioned.

We recognized that this was an issue for most people with rheumatism, and especially young people. Therefore, we wanted to start a conversation about how it is to go through life with an invisible disability.

The main purpose with our campaign was to acknowledge the fact that you can't always tell whether or not a person has a diagnosis, or is in pain. We also wanted to show young people with rheumatism that they are not alone in their situation.

Methods: We searched for young people with rheumatism in different ages and with different diagnoses. Each person in the campaign is presented in two different photos. One standard full-portrait photo in front of a white background, just showing who they are. One person held a basketball to show off her love for the sport, another one was wearing her dancing shoes and so on. The other photo is instead set in a complete dark room, with the person posing in the same way but this time with their rheumatism-affected areas lit up. We used glow in the dark-body paint and a UV-light to create this effect.

Each pair of photos is put together with the person's story about their passion in life and what it's like to live and deal with an invisible disability.

The campaign was released on October 12th 2016, on World Arthritis Day, with an event at Astrid Lindgren's children's hospital in Stockholm. The photos were printed and presented on large boards together with the personal stories.

The first photo of the campaign, a group photo of everyone participating, was also posted on our social media on October 12th and then one pair of photos was posted every day during the following week. People were also told to share their own stories under the hashtag \#synsintefinnsinte

Results: The campaign ended up being our organization's most successful campaign to this date. The spread was especially great on Facebook, with the first post reaching nearly 50'000 people and the other posts reaching between 3'500 and 25'000 people every day. The campaign had more likes and shares on both Facebook and Instagram than any of our other campaigns has had so far. The opportunity to show the photos at Astrid Lindgren's children's hospital also brought health care into the campaign and attracted great attention on site. The photos combined with the personal stories make a powerful statement. We managed to show young people with rheumatism that they are not alone in their situation, and we look forward to the conversation continuing on at \#synsintefinnsinte

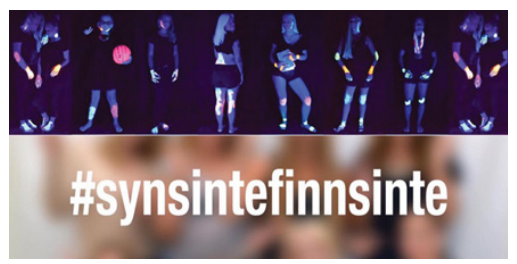

Disclosure of Interest: None declared

DOI: 10.1136/annrheumdis-2017-eular.4893

\section{FRIDAY, 16 JUNE 2017}

Imaging and treamtent response in rheumatology

\section{OP0283 ULTRASONOGRAPHIC EVALUATION IN RHEUMATOID ARTHRITIS USING THE GLOBAL OMERACT/EULAR ULTRASOUND SYNOVITIS SCORE (GLOESS)}

M.S. Stoenoiu ${ }^{1}$, A. Pesonen ${ }^{1}$, N. Bello ${ }^{2}$, R. Christensen ${ }^{3}$, M. Østergaard ${ }^{4}$, E. Naredo ${ }^{2}$, L. Terslev ${ }^{4} .{ }^{1}$ Rheumatology, Cliniques Universitaires Saint-Luc, Brussels, Belgium; ${ }^{2}$ Rheumatology, University Hospital Gregorio Marañon, Madrid, Spain; ${ }^{3}$ Musculoskeletal Statistics Unit, Bispebjerg and Frederiksberg Hospital; ${ }^{4}$ Center for Rheumatology and Spine Diseases, Copenhagen University Hospital, Rigshospitalet, Copenhagen, Denmark

Background: Recently, a global OMERACT/EULAR ultrasound (US) synovitis score (GLOESS) combining grey-scale (GS) and power-Doppler (PD) scores has been proposed as a novel measurement tool to assess disease activity and response to therapy in patients with rheumatoid arthritis $(R A)^{1,2}$. However, the ability of GLOESS to differentiate patients with different states of disease activity vs. remission in standard clinical care is not known.

Objectives: To assess the ability of GLOESS to discriminate between different clinical states of activity vs. remission in RA patients, and to compare clinical, GLOESS and PD US remission criteria and scores in a cross-sectional study.

Methods: Eighty RA patients from 3 centres were recruited at consecutive clinical visits: $50 \%$ were in remission and $50 \%$ had active RA according to Simple Disease Activity Index (SDAI). SDAI, Clinical Disease Activity Index (CDAl), 28-joint Disease Activity Score (DAS 28CRP), Health Assessment Questionnaire (HAQ), ACR/EULAR remission criteria were assessed. An independent investigator unaware of clinical results performed all US joint examinations of 26 joints. GLOESS, PD, and GS US sum scores per patient were assessed using OMERACT definitions. PD US remission was defined as the PD sum score $=0$. GLOESS remission was defined as GLOESS score $\leq 1$ thereby also including possible GS grade 1 .

Results: PD US remission was observed in $38(48 \%)$ patients and GLOESS remission in $16(20 \%)$ patients. SDAl $(r=0.24 ; p=0.03)$ and $\operatorname{CDAl}(r=0.23 ; p=0.04)$ but not DAS28CRP $(r=0.21 ; p>0.05)$ were weakly correlated with GLOESS scores in the whole joint set. SDAI $(r=0.41 ; p<0.001)$, CDAl $(r=0.40 ; p<0.001)$, and DAS28CRP $(r=0.40 ; p<0.001)$ were moderately correlated with PD activity in the whole joint set. A minority of patients were classified both in GLOESS remission and in clinical remission according to SDAI $(n=10)$, to CDAI $(n=10)$, to DAS28CRP $(n=10)$ and to ACR/EULAR $2011(n=7)$. Less than one third of patients were classified both in PD US remission and in clinical remission according to SDAI $(n=22)$, to CDAl $(n=26)$, to DAS28CRP $(n=27)$ and to ACR/EULAR $2011(n=21)$. The proportion of patients in clinical remission was significantly different according to the definition considered: while $50 \%$ of the patients $(n=40)$ were classified in remission according to SDAI, $58 \%(n=46)$ were classified in remission according to DAS28CRP, and $43 \%(n=34)$ according to CDAI and $43 \%(n=34)$ according to ACR/EULAR 2011 remission criteria.

Conclusions: We document major discrepancies between US and clinical findings and between clinical scores classifying patients in active disease vs. remission. Patients reaching GLOESS or PD US definitions of remission are partly different from those reaching clinical definitions of remission.

References:

[1] Naredo E, et al. The OMERACT ultrasound task force-status and perspectives. J Rheumatol. 2011;38(9):2063-2067.

[2] D'Agostino MA, et al. Exploring a new ultrasound score as a clinical predictive tool in patients with rheumatoid arthritis starting abatacept: results from the APPRAISE study. RMD Open. 2016 5;2(1):e000237. doi: 10.1136/rmdopen2015-000237.

Acknowledgements: We acknowledge P. Durez, B. Lauwerys, A. Durnez, A. 